\title{
Psychology Regulates Activity in the Social World
}

\begin{abstract}
Moving on from biology to psychology, we propose that the core function of the psychological is agency. This conception of the psychological in the new reworked biopsychosocial theory is consistent with current psychology and neuroscience, for example the so-called 4 Es model of cognition as embodied, embedded, enactive and extended. Agency has conditions in the social and political domains-signified by concepts of autonomy and recognition-the failure of which can jeopardise the perception and exercise of agency and hence psychological health. The third component of the biopsychosocial-the social-is defined within this framework as essentially to do with control and distribution of the resources necessary for biological and psychological life. The main theme of biopsychosocial interactions threads through the chapter, including theorising the notorious (for reductionism) 'topdown' causal pathways. This chapter aims to provide a framework to understand how factors involved in health and disease, particularly in the contexts of public health, and managing with long-term conditions, are increasingly seen to extend beyond the internal biological environment into the psychological, social, economic and political conditions of living.
\end{abstract}

Keywords Agency - Biopsychosocial systems - Embodied cognition • Post-dualism - Social determinants of health - Top-down causation

D. Bolton and G. Gillett, 


\subsection{The Psychological as Embodied Agency}

\section{Mind Is Embodied}

The decisive break from dualism in psychological science came with the development of the information-processing paradigm from around the 1960s onwards, in parallel with its development in biology. The paradigm ties together the biological and the psychological. Biology as physiology and anatomy deals with the body inside the skin, while psychology as behavioural science models functioning of the whole organism in its external environment, regulated and controlled by the central nervous system. The complexity of living beings increases massively in phylogenesis and ontogenesis and for human beings in maturity, behavioural science becomes psychology, and the information-processing paradigm is alternatively called the 'cognitive paradigm'. The paradigm shift was gradual: the early cognitive models were not primarily biological, relying on concepts like computation (operations on symbols), and representations, as if of some independent reality already there fixed. Subsequently, the models have become more biological, using models of embodied cognition involved with action [1-3].

Recent developments include 4E cognition [4], which characterises cognition in these four interconnected terms:

1. 'Embodied' (in the body)

2. 'Embedded' (in the environment; in causal loops with it)

3. 'Enactive' (Acting in and manipulating the environment, directly, not via a representation or model; the environment offers affordances, or opportunities, for action and manipulation)

4. 'Extended' (Extended to the body and environment, including devices used for cognitive functioning).

Embodied cognition involves the whole body, is action-based, dynamical, involving feedback loops, comprising sensory inputs, cognition as prediction, affect, decision, motor planning, modification by experience, and so on, all fundamentally in the service of action in the environment. The new approach is biopsychological but the psychological soon merges - along with the biological—into the social, because the environment is for us substantially social. The fundamental connection between cognitive and social processes, involving such as attention, memory and 
thought, was identified in the 1920s by the psychologist Lev Vygotsky [5]. Social, interpersonal processes pervade the aspects of cognition identified by the new $4 \mathrm{E}$ model (e.g. [6]).

This new view of the psychological can be called 'embodied agency' for short. The term captures two ideas that are fundamental themes in the biopsychosocial model being developed here: first, that the ' $\mathrm{I}$ ' that knows, the psychological, is also (in) an object among others, a biological body; and, second, that the biopsychosocial individual, the person, is an active, causal power. The broad paradigm of embodied agency in the current science constitutes a new view of human nature, replacing the dualism that, while formulated in the seventeenth century, remained with great influence as psychological science emerged in the nineteenth century into the twentieth century. The new approach appeared, as is sometimes the case, earlier in philosophy than in the science. Critical concepts relating cognition to embodiment and action appeared in nineteenth-century post-Kantian philosophy, especially in the so-called phenomenological tradition, with clear, explicit expression by the mid-twentieth century in Maurice Merleau-Ponty's work [7].

The concept of embodied agency is fundamental in the biopsychosocial theory of health and disease. It links physical with psychological health and implicates pathways between them. We will argue that psychological health depends on the development of a viable enoughfor the person-sense of agency, such that, if this condition is not met, mental health is jeopardised, and so also, via complex biopsychological pathways, is physical health. The conditions of embodied agency are biopsychosocial; they are drawn out through this chapter and their relevance to health through Chapter 4.

In the new theoretical approach based on the concept of embodied agency, the whole acting body is involved, but the nervous systems have a specific role in processing information, organisation, regulation and control. We quote below descriptions of the several nervous systems, in lay terms for the public, on the website of the Science Museum in London. The quotations, which are under the main heading 'Who am I?', illustrate the current science moving into culture, and several key interconnected points relevant to the line of thought we are pursuing here: first, that mind and body are thoroughly involved with one another, replacing mind-body dualism; second, that in this context the body is characterised not in mechanical terms, but in terms of functional processes involving information transfer and control; third, that these processes 
are not limited to the brain, but pervade the several nervous systems and their functional relationships that extend throughout the body and into processes that we do not think of as mental at all (such as digestion and temperature control). In short, mental functioning is entangled with biological functioning. The quotations from the Science Museum as follows $[8]$ :

What does the central nervous system do? Your spinal cord receives information from the skin, joints and muscles of your body. It also carries the nerves that control all your movements. Your brain is the most complicated part of your nervous system. It receives information directly from your ears, eyes, nose and mouth, as well as from the rest of your body via the spinal cord. It uses this information to help you react, remember, think and plan, and then sends out the appropriate instructions to your body.

What does the peripheral nervous system do? Some of your peripheral nervous system (PNS) is under your voluntary control - the nerves that carry instructions from your brain to your limbs, for example. As well as controlling your muscles and joints, it sends all the information from your senses back to your brain. Other parts of your PNS are controlled by the brain automatically. This is the autonomic nervous system. It manages some things your body does 'without thinking' like digestion and temperature control.

What does the autonomic nervous system do? There are three parts to your autonomic nervous system: 1 . The sympathetic system is responsible for your body's 'fight or flight' reaction. 2. The parasympathetic system looks after the workings of your body during rest and recuperation. It also controls your heart rate and body temperature under normal conditions. 3 . The enteric system controls the workings of your gut.

The radical shift in thought in this early twenty-first century account of 'Who am I?' compared with Descartes' seventeenth-century answer to the same question in the Second Meditation can be readily seen [9] (pp. 75 and 112):

But what then am I? A thing that thinks. What is a thing which thinks? It is a thing which doubts, understands, affirms, denies, wills, refuses, which also imagines and senses....

Because, on the one side I have a clear and distinct idea of myself, insofar as I am only a thinking and unextended thing, and as, on the other, 
I possess a distinct idea of body, inasmuch it is only an extended and unthinking thing, it is certain that this I... is entirely and absolutely distinct from my body, and can exist without it.

The twenty-first-century version, by contrast, has me and my body entangled together. And, connected, my body is far from 'simply an extended thing'; it is something more able to be a thing that thinks.

One implication of the radical shift from Cartesian dualism to the current science is that neural structures and activities become a new source of information for models of mental functioning. Neuroscience is a new third epistemology of mind, adding to the two we already have: recognition of mentality in (the regulation of) behaviour, and introspective reports or declarations. Neuropsychological findings can help shape, for example, the theory of colour vision [10], and models of memory [11] (p. 71). This new epistemology has major application in the theory of the extent to which psychological processes can affect biological processes, interpreting this question as the extent to which central nervous system pathways, especially those associated with modification by voluntary control or practice, affect biological processes. This in turn has application to health-related processes. For example, pain has been shown to be sensitive to central as well as peripheral pathways (to be considered in Chapter 4, Sect. 4.2), while biologically original and fundamental processes such as cell respiration and replication, and their dysfunctions, are probably not, nor the formation and travel of venous thromboembolisms.

The new model of embodied cognition include cognitive psychology and its well-known maxim, used to mark the contrast with behaviourism and unreconstructed conditioning theory, that we respond to the environment as perceived by us, not to stimuli given absolutely. This is a point about human psychology, but there is a broader point that belongs to the information processing paradigm generally, namely, that biological systemic functioning uses information detectors sensitive to specific kinds of signals within a certain range that is relevant to functioning. Biological systems are attuned to particular salient environmental signals, either genetically, or, as a result of learning, as modelled in behavioural learning theory. This is a core working assumption of the new epistemology in the current life and human sciences and accordingly it has multiple linkages. In biology, genetic functioning and environmental interaction are entangled in evolution by natural selection, and ontogenetically 
in gene environment interactions, to be considered later (Sect. 3.4). Moving to mature human psychology, the topic of the current chapter, the person's perception of reality-whether of themselves, their body and mind, or the world around them including friends and the wider culture-and their responses to it, depend on their interests, needs and values. This epistemology puts the person and their psychology at the centre of the biopsychosocial complex, as the knowing agent, though muddled up with biology and culture. The person is therefore also the centre of attention in biopsychosocial healthcare-a point to be made later in Chapter 4, Sect. 4.2. A specific illustration of the critical role of the person's interpretation of reality came up in Chapter 1, Sect. 1.2, as the epidemiological finding that perception of one's own social status is a better predictor of health outcomes than objectively measured social status. On the other hand, cognitive psychology and the new epistemology of which it is part is not 'idealist'. This is to say: it does not suppose that reality is only appearance. The new epistemology does not have reality as something 'behind' appearance, however, likely to be unknowable, but rather as appearance that is independent of our control. Reality makes itself well-known to us as events beyond our control which seriously impinge on our perceptions, needs and values; such as, serious losses, accidents, war, illness and impending death. Another aspect of the same point links with misperception and epistemological disorder. While we have latitude on how we represent reality we do not have a free hand, and if we go too far adrift in tracking it, we are potentially exposed to harm, and if and when we persist we are cognitively incompetent or in denial, and as more harm accrues, in a mental health condition. In the new philosophical framework, the ontology and epistemology of appearance and reality can be run in terms that overlap with health and disease.

\section{Agency Is Causal}

Nervous systems regulate internal and external behaviour. Central nervous systems have a super-status, though un-omnipotent, controlling other regulatory systems and behaviour as a whole, and all this reaches its peak in the human central nervous system, the largest and most complex, with highly developed specialised cortical areas and connections with so-called 'executive' functions. This from The University of California website [12]: 
The term "Executive functions" refers to the higher-level cognitive skills you use to control and coordinate your other cognitive abilities and behaviors. The term is a business metaphor, where the chief executive monitors all of the different departments so that the company can move forward as efficiently and effectively as possible. Who we are, how we organize our lives, how we plan and how we then execute those plans is largely guided by our executive system.

Executive functions can be divided into organizational and regulatory abilities. Organization includes gathering information and structuring it for evaluation. Regulation involves evaluating the available information and modulating your responses to the environment.... The executive system involves the prefrontal cortex, basal ganglia and thalamus... The frontal lobes are the last areas of the brain to fully develop. This area of the brain was evolutionarily late to appear and is much larger in human beings than in our closest non-human primate relatives. The frontal lobes typically account for about $40 \%$ of the human brain.

Self-regulation is one aspect of the causal power of agency among several, all entangled. Most plainly, embodied agency interacts with other physical things; it cannot act at all without supporting ground; the body as a physical thing, using the skeletal muscular system, can move other physical things, and is moved by other physical things. All these interactions involve energy transfer according to Newton's laws. The behaviour of the skeletal muscular system towards goals in relation to the environment and the effects of on-going behaviour is self-regulated, involving the nervous systems and executive functioning specifically, as above. Further, our activity in the social environment involves inter-regulation, this interspersed with physical interactions between us, benign or harmful. These themes of agency, inter-agency and causation run through the biopsychosocial in health, disease, security and injury, and hence they appear explicitly or implicitly throughout this book.

A recently proposed and influential philosophical theory of causation, the so-called 'interventionist' theory—see, for example, James Woodward [13] —emphasises linkage between causation and agency, consistent with what is suggested here. The interventionist approach emphasises that our interests in causal connections and explanations are linked to our practical concerns of being able reliably to bring about changes. At the same time the interventionist approach is aligned with experimental methodology, especially its technological implications: if A causes B, we can manipulate B by manipulating $\mathrm{A}$. Thus it 
has application across the sciences. The practical, technological emphasis of the interventionist approach to causation is particularly well suited to identifying specific, localised causal connections in complex systems, as opposed to causal connections covered by general laws, and has been developed more in connection with biology and neuroscience than physics. Particularly relevant to a core theme in this book, the interventionist approach can accommodate causation by regulatory mechanisms, including explanations involving non-events, of the sort considered in Chapter 2, Sect. 2.2.

\section{Embodiment Involves Intersubjectivity}

The Cartesian philosophy and its legacy was fundamentally solipsistic in the sense of envisaging only a single, unique subjectivity. It was not, at its foundations, social. The Cartesian ego, divorced from the body, never could know another subjectivity like itself: all the Cartesian ego could ever come across were objects of one sort or another; mechanical things in nature, including the body, or else perceptions in the mindbut it never could encounter as an object of knowledge another knowing subject like itself. For another subject to be an object of knowledge, subjectivity has to be something in the world that is known-that is, embodied. The dismantling of the seventeenth-century materialist-dualist thought framework involves not only embodiment of subjectivity, but intersubjectivity: the social assumes a foundational role. Embodiment and intersubjectivity make an appearance in philosophy following Kant in Fichte and Hegel: the knowing 'subject' becomes the human being, down to earth, as opposed to being disembodied, transcendental (outside of material, space and time) - and as such it is able to recognise another like itself (see, e.g., [14]). The foundational linkage in post-dualism between the biological body, knowing subjectivity and the social, becoming then moral and political, all with implications for the theory of health and disease, threads through these middle sections of this essay.

Inter-subjectivity opens up whole new aspects of regulatory control and communication. It involves interaction, between bodies and minds, involving both energy-exchanges and information-exchanges. We do not exchange information with the natural, inanimate environment: the flow of information is one-way, from it inwards to us; we do not send information to it to influence it; it has no information receptors or processing 
mechanisms; no systems functioning towards ends. In the social environment, however, all this changes, another aspect of the interpenetration of the psychological and the social.

\subsection{Biopsychosocial Conditions of Agency}

\section{The Concept of Agency Has Broad Scope}

Agency as the fundamental post-dualist concept spins off in many directions, with many alternative or related names; it threads through and criss-crosses the sciences and humanities: biology and neuroscience, psychology and its many subdivisions, especially social and developmental psychology, the philosophy of language and moral theory, social science and politics. The title of this section 'conditions of agency' refers in all these directions. We do not aim to review the science or the philosophy, but, consistent with the method so far, to clarify the conceptual and scientific foundations of the theory which replaces physicalism, dualism and reductionism, and which is required to underpin the biopsychosocial model of health and disease. As indicated, these foundations turn out to involve much more than biology.

\section{Biopsychological Preconditions and Implications}

Agency requires brain maturation and skill acquisition through infancy and childhood to adolescence, addressed in the increasingly intertwined developmental psychology and developmental neuroscience literatures (e.g. [15]). Subjectively, alongside and interacting with practical competence, with complex neuropsychological underpinnings, we develop the experience of agency. Here, for example, the beginning of a paper by Synofzik and colleagues presenting a general model of the experience of agency as based in an interplay between prediction and postdiction [16] (p. 1):

The experience of agency, i.e., the registration that I am the initiator of my actions, is a basic and constant underpinning of our interaction with the world: whenever we grasp, type, or walk, we register the resulting sensory consequences as caused by ourselves.

Here can be seen from another perspective the tight link between agency and self-causation. And as always in regulatory and control processes, there is the possibility of error; one of the applications of the research 
programme on the sense of agency is to some of the signs and symptoms associated with the diagnosis of schizophrenia.

A new field in neuroscience is the development of the social brain in adolescence, interwoven with increasing executive functioning. This abstract from a review article by Sarah-Jayne Blakemore and Suparna Choudhury [17] (p. 296):

Adolescence is a time of considerable development at the level of behaviour, cognition and the brain. This article reviews histological and brain imaging studies that have demonstrated specific changes in neural architecture during puberty and adolescence, outlining trajectories of grey and white matter development. The implications of brain development for executive functions and social cognition during puberty and adolescence are discussed. Changes at the level of the brain and cognition may map onto behaviours commonly associated with adolescence. Finally, possible applications for education and social policy are briefly considered.

The concept of 'agency' also appears as 'self-determination' in the theory of that name proposed by Edward Deci and Richard Ryan, social and clinical psychologists. Here, for example, [18] (pp. 227):

Self-determination theory (SDT) maintains that an understanding of human motivation requires a consideration of innate psychological needs for competence, autonomy, and relatedness... Social contexts and individual differences that support satisfaction of the basic needs facilitate natural growth processes including intrinsically motivated behavior and integration of extrinsic motivations, whereas those that forestall autonomy, competence, or relatedness are associated with poorer motivation, performance, and well-being.

The linkage of self-determination to psychological needs and to wellbeing is the direction we are pursuing here. What we are proposing for the biopsychosocial model also has many points in common with Albert Bandura's social cognitive theory of agency $[19,20]$.

\section{Language an Instrument of Agency}

Information transfer is essentially involved with regulation; it pervades biological functioning, and equally pervades behavioural relations within 
species. Language is one of our human within-species signalling systems; we use it to let each know the current state of dynamical play, for reporting, and to influence one another, as command. It is an expression and an instrument of agency. At the same time as being inherently social, language is also the means of much of our thinking, our psychology, another aspect of the interpenetration of the psychological and the social. Much twentieth-century theory of language has worked its way around such points. Here, for example, one of the pioneers, Lev Vygotsky, the developmental psychologist, writing in the early 1930s [21] (pp. 69-70):

Children master the social forms of behaviour and transfer these forms to themselves... The validity of this law is nowhere more obvious than in the use of the sign. A sign is always originally a means used for social purposes, a means of influencing others, and only later becomes a means of influencing oneself. ... If we want to clarify genetically the origins of the voluntary function of the word and why the word overrides motor responses, we must inevitably arrive at the real function of commanding in both ontogenesis and phylogenesis.

The philosopher Ludwig Wittgenstein developed a new philosophy of language from around the 1930s based on action and communication. His Philosophical Investigations starts with examples of people cooperating and communicating when shopping and building [22] (paras. 1, 2 and 8), and comments in paragraphs 18-19:

Do not be troubled by the fact that languages (2) and (8) consist only of orders... It is easy to imagine a language consisting only of orders and reports in battle.- Or a language consisting only of questions and expressions for answering yes and no. And innumerable others.- And to imagine a language means to imagine a form of life.

In this context, the key question in Wittgenstein's philosophy of language becomes: what does it mean to follow a rule?-a topic closely linked to the concept of regulation that permeates current biological and behavioural sciences. The conclusion to Wittgenstein's analysis has rule-following in language closely linked with agreement in practice [22] (paras. 240-242). In biological inter-regulatory systems, the concord is set up by selective pressure over evolutionary timescales. 


\section{Agency as Moral Responsibility}

A strand in moral theory examines the logic and purpose of attributing moral responsibility (see, e.g., [23]). There are debates as to whether this presupposes free will, genuine self-determination, and in what sense, and debates as to whether praise and blame are made on merits, a matter of what is deserved, or as a means to influence the other. The first consideration links with further moral concepts, bringing in notions of justice, for example, while the second-attributing moral responsibility as means of influencing each other-highlights processes with direct connection to our current themes. Instructions or exhortations from one to another are backed up, if the necessary power asymmetries are in place, by moral sanctions, praise or blame, and these social-moral mechanisms of control, more or less benign, are internalised as we acquire prosocial behaviour.

In short, as agency interpenetrates the social it becomes involved with morality. The moral emotions such as shame and guilt, conversely feelings of self-worth, are fundamental to our psychological life, and when the negative emotions of self-blame become barely controllable, they figure prominently in health conditions. Attribution of illness involves excuse from blame, but also carries risk of suspicion and exclusion, issues taken up in the next chapter (Sect. 4.2). All these things involve much more than our biology and in the new biopsychosocial theory they are all relevant to health and disease.

\section{Agency as Autonomy Is a High Political Value}

Psychological agency merges into political autonomy. 'Autonomy' in the Greek refers to self-legislation. The term was applied originally in politics to self-governing states as opposed to colonies, was later employed in moral theory by Immanuel Kant in the high Enlightenment, becoming fundamental to liberal political philosophy [24]. Discussion of the various uses and meanings of autonomy which criss-cross the psychological and the political, and their relevance to the concept of mental disorder can be found in [25]. The concept of autonomy is also prominent in bioethics, affirming the right of the person in medical contexts to exercise control over what is done to his or her body, linking moral and legal rights with our biology [26]. The concept is also used in theorising the social gradient in health, referred to in Sect. 2.1. For example, Michael Marmot argues that it is not simply position in the hierarchy 
that accounts for worse health among individuals of lower status ... but what position in the hierarchy means for what one can do in a given society: the degree of autonomy and social participation' [27] (p. 1306).

Brain development of adolescents related to executive and social functioning was referred to above, and reappears here as the development of psychological and political autonomy. The adolescent becoming adult is recognised as an independent citizen, capable of work and contracts and childcare, for example, with assumption of moral and legal responsibility. These processes run across sectors and scientific disciplines-illustrating how split-up sciences and policies have to work together to grasp the development of the biopsychosocial being - and they all impinge on aspects of adolescent health problems - on risks, management and recovery.

\section{Agency/Autonomy Depend on Recognition}

Agency in interpersonal and political activity depends on the person as agent being recognised as such. There is a close linkage between embodied, active cognition and intersubjectivity in post-Kantian philosophy, noted above Sect. 3.1, and intersubjectivity is interwoven with the recognition problem. Hegel has a famous passage in the Phenomenology of Spirit on the meeting of two people and processes of mutual recognition [28] (pp. 86ff.). He develops a complex argument to the effect that recognition of the other is essential to the development of self and self-consciousness, and it may well be that something of that sort is correct. The context in Hegel is the philosophical project of absolute knowledge that for present purposes was transitional and is irrelevant. The application here is that the philosophical foundations of biopsychology include social recognition as necessary for the development and exercise of agency. Recognition involves social power balances. In Hegel, the appearance of the concept is immediately politicised, with argument to the effect that recognition is impossible in the 'lordship-bondage' or 'master-slave' relationship. Subsequently, the concept has been used in political philosophy to theorise the dynamics between more and less powerful groups (e.g. [29-31]).

In benign, caring social groups, with participating members well enough disposed towards one another-functional families, kinship structures, cohesive communities-people recognise one another: they know how to respect each other's agency, albeit within socially 
proscribed rules and regulations, how to care for, educate, provide opportunities and cultivate voice and practice in children. In short, inclusive communities provide conditions for agency, albeit subject to its rules. If however such communities are excluded from access to resources by more powerful forces, community and individual autonomy is threatened, raising risk of ill health at both levels. These issues are taken up in the next section.

\subsection{The Socio-Political: Who Gets TO CONTROL What?}

\section{Regulatory Control of Biopsychosocial Resources}

The 'social' is the third component of the triumvirate invoked by the Biopsychosocial Model as relevant to health and disease, and we turn now to consider it. However, we have already had to start this in the preceding section on the psychological as agency. Because agency involves exercise of power, it is highly sensitive to uses and abuses of power, to the political. Social processes are approached in the social sciences directly however, not via the psychological as agency, but similar themes appear either way round.

The subject matter of the social sciences can be described in terms of social structures, functions, organisation and regulation. This is consistent with the view proposed here that these and related concepts and principles are found throughout the biopsychosocial. Two main themes in the social domain are group cobesion and allocation of resources, and both are implicated in models of health and disease. As considered at the end of the last section, cohesive communities such as kinship structures can provide conditions for agency, subject to their rules and regulations. We turn here to consider the theme of distribution and allocation of resources.

The distribution of resources, prioritising among needs, prioritising between recipients, is a fundamental feature of social groups, from families to the state. It is a vast elaboration of the sort of distributive, prioritising processes already apparent in basic biological control systems, the delivery of chemicals necessary for Krebs' cycle, for example, and the control of metabolic processes by the nervous system. Control mechanisms that up- or down-regulate resource allocation are causal: 
they make a difference to what happens. In the social world, a general word for this kind of causal control is 'power'. Distributive and prioritising functions are defined by socio-economic rules and regulations, backed up by state or non-state power, with sanctions involving the use of force and the deprivation of autonomy and liberty. The exercise of power is one defining characteristic of politics, and in this sense 'the social' in biopsychosocial theory applied to health, to do with the distribution of resources, is essentially 'the political'. The highly influential political scientist Harold Lasswell clearly identified this point decades ago, and one of his major works has the title: Politics: Who Gets What, When, How [32].

Resources needed for biological health include-no surprises hereaccess to energy-related provisions, such as food, clean water, shelter to help maintain body temperature, at minimum, extending to healthy diet and exercise opportunities. As the biomedical sciences have understood progressively more detail of our internal biology, so our biological requirements have become more understood. These requirements are basically met by the environment, and as the environmental sciences have understood progressively more about environmental conditions, local and global, so our environmental requirements have become more understood, along with threats. All these well-worked areas are signalled here as part of the biological-environmental-social-psychological whole picture, and to make the uncontroversial point that socio-political processes regulate and control distribution of physical, chemical and biological resources, according to wealth and wealth differences or alternatively according to principles of social justice. The more access to resources, at the individual or population level, the lower the risk of disease. The same point reappears post-onset. The more wealthy a person or state, the sooner healthcare can be accessed, the better the detection and treatment, and the better chance of favourable outcome. All this is well-known and well-understood. We focus more on the more recently recognised and less well theorised causal interplay between socio-political control of processes affecting psychological health - and hence, via that pathway, biological health.

As argued so far, social structures can cultivate agency or they can inhibit it. If a person or group controls the action of another person or group, they so far fail to recognise the agency of the other, and tend to control the interaction in such a way as to disqualify it. Agency can be denied by various processes of psychosocial exclusion: if a person is not 
noticed, not consulted, not listened to, has no place at the table when important decisions affecting them are being made-then, so far, they have no opportunity for agency in the social group. Options collapse: to withdrawal from free action, to doing only what is prescribed by more powerful others-typically under threat of sanctions for disobedience and disruption, sanctions typically involving brute, physical-biological force. Conversely, when agency is recognised, insofar as the person is allowed and encouraged to have their voice and to influence affairs, agency is realised. This intersubjective relationality can be expressed by saying, somewhat paradoxically, that one cannot be an autonomous agent all by oneself, a point emphasised in feminist theory [33].

Social exclusion has been explored more in political philosophy and related social theory than in psychology. We referred previously to Hegel's theory of recognition and just above to feminist theory. Other relevant active literatures are critical race theory (e.g. [34]), and postcolonial studies (e.g. [35]). Related philosophical theory includes Miranda Fricker's important new concept of 'epistemic injustice' [36] and the related notion of 'epistemic violence' (e.g. [37]). The core idea is that a person's epistemic status - their status as a knowing agent-can be undermined and disqualified by prejudicial use of power. The role of epistemic disqualification in theorising health risks has still to be worked out.

Social exclusion mechanisms involve micro-interpersonal and macrosocial interactions that can operate at any or all points in the lifespan. Others relate specifically to access to resources and opportunities necessary for development of agency in children. Agency requires the development of knowledge and skills and therefore depends on access to and quality of education and training, in turn typically linked to privileged group membership. Socio-economic-political power structures keep a tight hold on distribution of education and training resources, and this is another factor-along with and interwoven with distribution of biological resources-that maintains linkage between wealth and health. Greater access to education and training tends towards greater employment prospects and hence greater social status and wealth, creating a benign circle; and conversely. This is part of the biopsychosocial background of the so-called 'social gradient of health', reviewed below in Sect. 2.1, a linking mechanism being chronic stress, to be considered in Chapter 4, Sect. 4.3. 


\section{Socio-Political Causes Really Ave Causes}

The arguments so far are relevant to disputes in epidemiology regarding the causal status of the social determinant of health. In the reductionist world picture, only physical-chemical biological causes are real, while psychological and social causes are chimerical. In this picture, associations between poverty and poor health could be explained in terms of biological processes such as poor diet, hygiene or smoke inhalation, while social factors are something else, kind of causal, but not really, because not biological. The social factors appear less like causes, more like delivery or exposure processes, as opposed to the really causal biochemical or microbiological mechanisms-all these thoughts summed up in the idea that social factors are not real causes but something else, perhaps 'distal risks'. The counter-argument developed here is that delivery and differential exposure processes are equally causal, apparent already at the basic biological level. The problem and counter-argument in more detail as follows.

Here is William Cockerham in his book Social Causes of Health and Disease [38] (p. 1; citations omitted):

Stress, poverty, low socio-economic status, unhealthy lifestyles, and unpleasant living and work conditions are among the many inherently social variables typically regarded by laypersons as causes of ill health. However, with the exception of stress, this view is not expressed in much of the research literature... Usually social variables are characterised as distant or secondary influences on health and illness, not as direct causes. Being poor, for example, is held to produce greater exposure to something that will make a person sick, rather than bring on sickness itself...

Other epidemiological theorists have echoed this complaint, for example, Kelly and colleagues [39] (p. 310):

The importance of behavioural and social factors notwithstanding, they seldom find their way into etiological discussions of mechanisms of causation, instead being merely defined as risks or risk factors.

This is a major issue in the epidemiological literature. In her important paper on epidemiology and causation, Nancy Krieger [40] argued that while the epidemiological literature since the 1960s has recognised complex multifactorial causation, it became preoccupied with statistical 
modelling, without developing an adequate theory of causation. In a later paper Krieger argues, consistent with the views proposed here, that power-power over and power to do-structures people's engagement with the world and their exposures to material and psychosocial health hazards, driving health inequities, and that power does not readily map onto a metric of proximal or distal [41].

A related issue is whether apparent social causes are really confounded by biological causes. Here is Michael Marmot, discussing this issue, arguing that social factors, and a biopsychosocial model, have to be invoked to explain the social gradient in biological health risks [42] (p. 43):

Coming back to the Whitehall study, people had the idea that if we could explain the gradient in CHD [coronary heart disease] mortality by cholesterol, then social class would not be causal. I think this is too simplistic, because social class can determine the cholesterol level... In fact, mean plasma cholesterol in the first Whitehall study was marginally higher in the top grades and in the Whitehall II study there was essentially no difference by grade of employment. In both studies there was a very clear social gradient in smoking.

This comes back to asking the question of why we need a Biopsychosocial Model if we have smoking? An important psychosocial question is why is there a social gradient in smoking? It is not enough to know that smoking causes disease. We need to know why it is in the UK as a whole, close to $100 \%$ of women and $80 \%$ of men in the most deprived category are smokers...

In the terms of the view proposed here, the causal status of social determinants of health has seemed problematic because of a mistaken conception of causation, limited to biology, but biology presumed to be a matter of physics and chemistry, and therefore quite unlike social mechanisms that deliver health resources or toxins to exposed populations. Once understanding of biological causal explanation is updated in line with the biological and biomedical science of the past few decades, it can be seen to comprise not only physics and chemistry, but also and in very large part specification of mechanisms that organise and deliver resources all around internal biological systems, and which remove toxins, or fail to; and further, those internal distribution processes are entirely dependent on what can be taken in from the external environment, clean air and healthy diet, for example, or the opposites, in which case any social mechanisms such as social inclusion and exclusion that affect availability 
of health-promoting resources or exposure to toxins are very much part of the causal chain, whether distal or otherwise.

As Marmot implies in the above quote, we need a broader biopsychosocial model to comprehend social causal processes as well as and interacting with biological causal pathways. Such a model also brings into view the psychological and its relation to the social, including distribution of resources that promote development and exercise of agency, such as education, employment, and social cohesion that can cultivate agency. Insofar as societies are organised so that these are not available to particular groups, the individuals in those groups are at raised risk of psychological health difficulties as well as physical health difficulties, and either way this social risk raising is causal.

The statistical modelling of multifactorial causal interactions, especially in non-linear systems involving feedback/feedforward effects over time, presents challenges in epidemiology. Galea and colleagues [43] examine the issues in the case of 'the cause of obesity', listing seven broad headings of types of relevant factor, each with many specifics, from genes and gene expression through to national food and agriculture policy, with many individual, neighbourhood and social levels in-between. The authors note, consistent with the view proposed here, that higher level social factors are indeed causal, and go onto to consider the counterfactual approach to identifying a single modifiable causal factor, and the use of multilevel regression modelling of multiple risks. They note, however, the limitation of regression to capture non-linear effects of the outcome dependent variable(s) on the independent variables, and propose use of complex systems dynamic computational models which can take into account not only risks at multiple levels but also interrelations between them.

The topic of this section, social causation, is a long-standing major topic in the social sciences. The hermeneutic tradition, which defined social processes, meaning and understanding, as separate from causal explanation of nature by physics and chemistry, as outside nature and causation altogether, was briefly discussed in Chapter 1, Sect. 1.3. The hermeneutic approach is also consistent with emphasising that individual psychology and action underpins social phenomena, a view associated with Max Weber and known as 'methodological individualism' in the social sciences (for review see, e.g., [44]). Another tradition, from Émile Durkheim, proposes that the subject matter of the social sciences are distinctive social facts and causal processes. This kind of approach, sometimes called 'methodological holism' (for review 
see, e.g., [45]), can be seen as opposed to methodological holism, requiring reconciliation between the two views. For example, List and Spiekermann [46] propose reconciliation using concepts from current analytical philosophy of mind, such as 'supervenience'. Our approach to the relation between individual level and social level causal explanation is part of the general theory of biopsychosocial systems outlined in the next section.

\subsection{General Theory of Biopsychosocial Systems}

\section{The Thread so Far}

We pick up here the line of thought developing a general model of biopsychosocial ontology and interactions that was set up at the end of Chapter 1, Sect. 1.3. Throughout the chapters so far, the ontology and the theory of causation have been of a piece. The key principle in the ontology starts with the relation of biology to the physics and chemistry of matter. Within the constraints of energy equations, complex molecular structures form, capable of regulating energetic processes, especially increasing energy differences, running counter to the second law of thermodynamics, temporarily, though replicating in the meantime. Thus the ontology blurs into causal theory: different complex dynamical forms have different causal properties. This was the line of thought in the first part of Chapter 2. In the second part, the contrast was drawn with the limited, uniform, flat ontology of physicalism, which, in its most coherent form, would envisage only physical causation, but, faced with apparently valid causal principles in the psychological and social sciences, principles able to predict, retreats to the physicalist ontological claim only, admitting psychological and social causation, though inevitably has trouble theorising these additional causes without additional ontology. Now that we have in this third chapter so far proposed an account of the psychological and social, we can now generalise the points made in connection with biology to the psychological and the social.

\section{Life Forms: Diversity Amidst the Physics}

The idea proposed in Chapter 2 that biological forms and ends proliferate within 'free spaces' permitted by physics energy equations carries through to the biopsychosocial. As a rule, nothing in psychology 
or social science textbooks is ever going to contradict textbooks about human biological systems, and insofar as psychology has any invariants, they will be preserved in the social sciences. There are constraints, but they leave scope for variety. In this sense, psychology exploits biological indeterminacy, for example, in the individual differences that arise partly by genetic constitution and partly by individual learning experiences, expressed as individual choice and agency. Following the same line of thought, social processes elaborate diversity in the biological and the psychological, giving rise to many forms of practice around our biological nature and around agency, intersubjectivity and recognition. The transition from the biological to the psychological and the social is characterised by the appearance of new free spaces in which can arise the twin phenomena of new forms of organisation and diversity and with them new causal processes. Once we move above physics and chemistry into biology, hence into psychological and social processes, the causation involves information-exchange, communication, regulation and control.

\section{The Logic of Top-Down Causation}

There are many kinds of causal pathways in biopsychosocial systems. They can be top-down, bottom-up, and within-levels; they can involve regulatory mechanisms, disruptions to regulatory mechanisms, or have nothing to do with regulation, involving energy exchanges only. Already the abstract picture is complex, even before the specifics, and the contrast is with the single sort of causation envisaged by physicalism, energy transformations covered by a handful of equations.

Traditionally top-down causation has appeared as the most conceptually problematic, disallowed by physicalist reductionism, and behind that, by energy conservation constraints. The problem is relieved when causal processes involving regulation are acknowledged. In this kind of causation, the regulating mechanism and the processes regulated are in the same ontological space-signified exactly by the fact that they interact. In this sense, while we can say that the regulating mechanism is at a 'higher' level than the processes being regulated, this no longer has the connotation that belonged to the concept of level in reductionism, namely that lower levels are ontologically more basic than higher levels. A core principle is that control mechanisms can $u p$ - and down-regulate processes at a 'lower' level, but cannot change their conformity to the lower 
level laws. We considered this point in relation to biology, physics and chemistry in the second chapter, but it has some application throughout. In the case of the psychological, our biology gives us both capacity and choice-we have control over our limbs all being well, and some choice between courses of action-but we cannot alter our basic physics, biochemistry or biology: if the rope breaks we fall, if the biological mechanisms controlling cell replication breakdown we cannot by act of will put them right; we survive practically no time without oxygen. Equally, forms of social organisation can vary, but they cannot alter our biology; for example, there are many ways in which social groups organise themselves around death, but they cannot alter the fact, even if we freely imagine life after, or postpone it as long as possible by medical treatments. Or again, forms of social organisation can promote education and training of individuals, but there are limits to achievements deriving from common and individual biopsychology; and forms of social organisation deal with agency and recognition of the individual in the social group in diverse ways, but cannot alter our need for it.

The point that higher level processes can up- or down-regulate lower-level processes, but cannot change the causal laws or principles at the lower level, is clearest at the lowest level, physics and chemistry, where the energy equations never change. As we move away from the physi$\mathrm{cal} / \mathrm{chemical}$ laws, however, we never encounter inviolability again. As we move into biology, psychology, and social processes, there is increasing scope for higher level processes not only to up- and down-regulate, but also to affect the lower-level processes themselves, because these lower-level processes are themselves regulatory, not fixed laws of nature. There are some hard and fast rules, but blurred boundaries. For example, there is a boundary, but a blurred one, between biological processes that we can psychologically control—or can learn to control—and those we can't, and a blurred boundary between psychological processes that can be socially controlled, and those that can't. Once we move up from the inviolable laws of physics and chemistry - up from their mathematical equations - the new forms of organisation and principles governing change have themselves a changeable quality.

Biopsychosocial top-down causation is possible because the various systems are all in the same ontological space. Systemic top-down causation always involves agents at the lower level, where the difference is being made, but those agents at the lower level function in ways deriving from their communication- or information-based relationships with 
wider organizational/regulatory systems. Hormones are biochemicals like the processes they regulate, but their messenger function derives from the state of the brain or other organ that regulates their secretion, and that in turn on states of distant parts of the body. Social authority is imposed on individuals by other individuals, by virtue of their office, a complex idea that includes acceptance of the rules by all parties involved, and the power of the office to force compliance. Causation by regulatory control is not ethereal and mysterious: it involves interaction with the regulated processes by things of the same type, in the same ontological space, but those linked to wider contexts and dynamic relationships.

Psychological regulation of biological processes appears as the alternative to the irredeemably problematic Cartesian problem how immaterial mind could affect the material body. In post-dualist science, mental functioning is embodied, and the central nervous system regulates not only some internal functioning but also goal-directed behaviour in the environment. All of the processes occur in the same ontological space: stimuli are material forms, as are nervous system responses, as are behavioural responses. These forms exercise regulatory control over one another using information-exchange. Specification of a mechanism is specification of the intervening links, in terms of information exchange, up-/down-regulation of subsystemic responses, or whole behaviour responses, and/or in terms of the materials, such as neurons, neuronal assemblies, genes and hormones. Within this paradigm, with the concepts so constructed and ordered, specification of mind-body mechanisms is a scientific task-not a conceptually insoluble problem.

Social regulation of individual, psychological/behavioural processes has the same logic as psychological regulation of biological processes. Social and psychological/behavioural processes occur in the same ontological space; a military officer is a person like the private soldier. The question arises what are the causal properties of the individual person-as opposed to those of the office. Some causal properties of the individual are the same whatever social system they are in, biopsychological properties, let's call them, but others are by virtue of their office within a socially defined and regulated institution, realised in patterns of relationships and causal power within the wider social institution. Only by reference to the wider social institution is it possible to explain why the military officer can control the behaviour of the private soldier. All this is obvious enough; it is not ontologically mysterious. The appearance of mystery is only in the context of reductionism. Away from the 
reductionist picture, there is nothing ontologically mysterious about social institutions or their causal powers. An adequate explanation of why, for example, a military officer can do what he or she does, involves reference to the long-standing institution of the military, with its accumulated rules and regulations, to the training of the individual person within and by those institutions, and to their appointment as an officer, bringing with it access to power that far exceeds biopsychological nature understood as without institutionally defined office. Apart from causal power, membership of particular social groupings may affect individual psychological/behavioural dispositions. For example, members of disadvantaged groups lacking education are more likely to have lower health literacy and less timely access to healthcare. There can also be associations and possibly causal connections between social phenomena, for example, between state or non-state actors, or between socio-economic class and health outcomes, as evidenced in the social gradient in health. All such relations involve individuals, but some of their causal properties, both what they affect and what they are affected by, depends as much or more on socially defined position than on individual characteristics and differences. This general approach defuses the tension between individual level and social level explanations considered at the end of the previous section.

Biopsychosocial systems work by complex regulatory control mechanisms that are vulnerable to break down. At the same time, biopsychosocial systems tend to self-preservation for as long as possible, which, since the threat of breakdown is ever present, requires a special dedicated class of regulatory mechanisms that protect, disrupt, repair and restore-all more or less successfully. Study of such defensive and maintenance mechanisms take up substantial parts of biomedical and psychological textbooks, and there are social science analogues regarding mechanisms for maintaining social order.

\section{Cross-Disciplinarity and New Human Sciences}

The biopsychosocial/environmental whole can be divided up three or four ways, four to include the natural as well as the social environment, using distinctive methodologies to answer distinctive kinds of questions, and then much subdivided in the division of scientific labour. However, the signal from the changes in the life and human sciences reviewed here is increasing need for cross-disciplinarity. The biopsychosocial systems 
theory approach makes interdependency of the four kinds of phenomena fundamental, especially in modelling real-life problem areas. There is simply too much going on for one disciplinary approach alone. For example, biomedicine restricted to inner organs and systems will not attend much to the psychological attitude of the patient or their social and broad environmental context. The multifactorial and cross-disciplinary nature of the causes of variance in health outcomes also appears in the broad cross-sectoral range of interlinked outcomes, for example, links between health inequalities and educational inequalities (e.g. [27]).

In recognition of the need for cross-disciplinary approaches to problem-solving, they are increasingly encouraged by research funding bodies. For example, there is a new UK cross-research council strategy for mental health, which announces itself like this [47] (p. 1):

The Research Councils... collectively have an interest in mental health research from a medical, biological, environmental, cultural, societal, technical and historical perspective. We have worked together to develop a cross-disciplinary research agenda, to articulate opportunities for cross-disciplinary working.

The stronger signal from these developments however is that the old headings of sciences which gives the Biopsychosocial Model its name are themselves problematic, especially insofar as they still contain lingering presumptions and prejudices from the old divided spaces, and what is in progress is a biopsychosocial/environmental transdisciplinary revamp across the life and human sciences. It is as if we shouldn't really be starting where we are now, with biology, psychology and social science as separate from one another. These old sciences need reconceptualising so as to manage biopsychosocial and natural environment interactions. A further implication is that new, large scale scientific paradigms will involve these interactions as foundational.

This point applies to the two new, progressive sciences, mostly applied to health and disease: genetics and neuroscience. These two new sciences effectively break down previous categories of biological, psychological, environmental and social-they do not start with these four 'levels' of reality or causal explanation, but rather with an assumption more like bio-environmental-psycho-social integrity. Neuroscience works with a systemic view of the brain, essentially engaged in regulation and control of within-body processes and behaviour in the outer environment, 
implementing psychological processes, including substantial resources for social processing, while at the same time being biological, neurochemical, genetically influenced; and so on. The new genetics is plainly biopsychosocial, envisaging biological genetic influences, individual differences and social factors, among other environmental factors, as all involved in determination of phenotypes, including health outcomes. The most recently developing field of epigenetics illustrates these features most explicitly and some points are detailed below.

Epigenetic processes are potentially heritable changes in genetic effects on a phenotype that do not involve changes to the underlying DNA sequence. The genome itself is not altered, but specific genes can be expressed, i.e. can be active in the production of proteins, or they can be switched off and inactive-this altering downstream functioning in the internal or external environment. Proximate epigenetic mechanisms include DNA methylation and stable chromatin modifications, and the wider systemic picture has many factors capable of altering these epigenetic mechanisms, including other genes, biological clocks, and exposure to specific external environments. The concept of gene-environment interaction is grounded somewhat differently in molecular genetics and behavioural genetics, corresponding to their distinctive objects of study, concepts and methodologies. In molecular genetics, gene-environment interactions can be understood as effects of specific environmental exposures on gene expression, as above. Measuring gene-environment interactions is methodologically complex, requiring assessment of each component and causal role separately (e.g. [48, 49]). In behavioural genetics, the concept refers to differential phenotypic effects of the same environmental exposure on different genotypes, indexed by statistical interaction in the model.

Epigenetic mechanisms are biologically deep, found already in, for example, plants regulating responses to stress [50]. They appear in animals, the environment for mammals typically including maternal behaviour or other complex social interactions with con-specifics (e.g. [51]; [52]). Epigenetic factors have also been implicated in humans and human diseases, for example, in hypothalamic-pituitary-adrenal function [53] coronary heart disease [54], and in the social gradient of health [55].

A striking illustration of the interpenetration of biological, environmental and psychological processes is the possibility that individual agency qualifies the gene/environment dichotomy. It has been a startling 
finding in human behavioural genetics that environmental exposures, specifically adverse life events or risks, far from being all independent accidents, are sometimes themselves 'heritable'. Such gene-environment correlations seem to cast doubt on purely environmental causal effects. However, there is a more radical implication here. In their review of gene-environment $(\mathrm{G} \times \mathrm{E})$ interaction Manuck and McCaffery have this [56] (pp. 62-63):

An interaction confounded by rGe [gene-environment correlation] might well seem to lack the implications of a true $\mathrm{G} \times \mathrm{E}$ finding. Yet what is the implication, if not confirming a proposition predicated on a frayed dichotomy?... In view of the extent of demonstrated rGE, it seems reasonable to assume that most dimensions of measured experience will have both environmental and genetic determinants, and most $\mathrm{G} \times \mathrm{E}$ studies will not be able to partition genetic and environmental influences on their environmental moderators... Relinquishing pure $\mathrm{G} \times \mathrm{E}$ interaction as the grail of $\mathrm{G} \times \mathrm{E}$ research may encourage interest in a broader expanse of potential gene-exposure interactions affecting behaviour, such as those moderated by complexly determined experiences, dispositions, abilities, attitudes, and affective states.

A simple way of formulating the conceptual shift here is that while plants are sessile-fixed or in motion only because of some outside force such as ocean currents-animals use their own energy resources to move, and individual animals can move to varying environments, up to the point of human beings who have multiple possibilities as to what kind of place to be in and what kind of thing to do-although this within the options available to us - this in turn altering environmental exposure. Insofar as individual differences play in selecting among possibilities, the outcomes will be attributable to the person's individual nature, though this in turn dependent on genes and prior exposures and learning. Life and lifestyle choices, within the options available to us, are themselves influenced by all the factors that make us what we are: genes, upbringing, learning, values.

This has the radical implication that genes can play a role in determining the environment as environmental exposures, in addition to the point above that environmental exposures can determine gene expression. In combination, the implication is that dynamic interplay is fundamental, not separate categories. 


\section{REFERENCES}

1. Varela, F. J., Thompson, E., \& Rosch, E. (1991). The embodied mind: Cognitive science and human experience. Cambridge: The MIT Press.

2. Gillett, G. (2008). Subjectivity and being somebody: Human identity and neuroethics. Exeter: Imprint Academic.

3. Wilson, R.A., \& Foglia, L. (2017). Embodied cognition. In E. N. Zalta (Ed.), The stanford encyclopedia of philosophy (Spring 2017 Edition), URL $=$ https://plato.stanford.edu/archives/spr2017/entries/embodied-cognition/. Accessed 12/21/2018.

4. Newen, A., De Bruin, L., \& Gallagher, S. (2018). Oxford handbook of $4 E$ cognition. New York, NY: Oxford University Press.

5. Vygotsky, L. S. (1978). Mind in society: The development of higher psychological processes. Cambridge, MA: Harvard University Press.

6. Tollefsen, D., \& Dale, R. (2018). Joint action and 4E cognition. In A. Newen, L. De Bruin, \& S. Gallagher (Eds.), The Oxford Handbook of $4 E$ Cognition (pp. 261-280). Oxford: Oxford University Press.

7. Merleau-ponty, M. (2012). Phenomenology of Perception (D. A. Landes, Trans.). New York: Routledge.

8. The science museum how does your brain work? http://www.sciencemuseum.org.uk/whoami/findoutmore/yourbrain/howdoesyourbrainwork/. Accessed October 7, 2017.

9. Descartes, R. (2003). Discourse on method and meditations (E. S. Haldane \& G. R. T. Ross, Trans.). Mineola, New York: Dover Publications, Inc.

10. Aizawa, K., \& Gillett, C. (2011). The autonomy of psychology in the age of neuroscience. In P. M. Illari, F. Russo, \& J. Williamson (Eds.), Causality in the sciences (pp. 202-223). Oxford: Oxford University Press.

11. Bechtel, W. (2008). Mental mechanisms: Philosophical perspectives on cognitive neuroscience. London: Psychology Press.

12. The University of California. (2017). Frontotemporal dementia. http:// memory.ucsf.edu/ftd/print/book/export/html/684. Accessed October 7, 2017.

13. Woodward, J. (2003). Making things happen: A theory of causal explanation. New York, NY: Oxford University Press.

14. Bolton, D. (1982). Life-form and idealism. Royal Institute of Philosophy Lecture Series, 13, 269-284.

15. Leckman, J. F., \& March, J. S. (2011). Editorial: Developmental neuroscience comes of age. Journal of Child Psychology and Psychiatry, 52(4), 333338. https://doi.org/10.1111/j.1469-7610.2011.02378.x.

16. Synofzik, M., Vosgerau, G., \& Voss, M. (2013). The experience of agency: An interplay between prediction and postdiction. Frontiers in Psychology, 4(127). https://doi.org/10.3389/fpsyg.2013.00127. 
17. Blakemore, S. J., \& Choudhury, S. (2006). Development of the adolescent brain: Implications for executive function and social cognition. Journal of Child Psychology and Psychiatry, 47(3-4), 296-312. https://doi. org/10.1111/j.1469-7610.2006.01611.x.

18. Deci, E. L., \& Ryan, R. M. (2000). The "what" and "why" of goal pursuits: Human needs and the self-determination of behavior. Psychological Inquiry, 11(4), 227-268. https://doi.org/10.1207/s15327965pli1104_01.

19. Bandura, A. (2006). Toward a psychology of human agency. Perspectives on Psychological Science, 1(2), 164-180. https://doi. org/10.1111/j.1745-6916.2006.00011.x.

20. Bandura, A. (2008). Reconstrual of "free will" from the agentic perspective of social cognitive theory. In J. Baer, J. C. Kaufman, \& R. F. Baumeister (Eds.), Are we free? Psychology and free will (pp. 86-127). New York, NY: Oxford University Press.

21. Vygotsky, L. S. (1990). The genesis of higher mental functions. In K. Richardson \& S. Sheldon (Eds.), Cognitive development to adolescence (pp. 61-80). Hove: Lawrence Erlbaum Associates.

22. Wittgenstein, L. (1953). Philosophical Investigations (G. E. M. Anscombe, Trans.). Oxford: Blackwell.

23. Eshleman, A. (2016). Moral responsibility. In E.N. Zalta (Ed.), The stanford encyclopedia of philosophy (Winter 2016 Edition). URL $=<$ https://plato. stanford.edu/archives/win2016/entries/moral-responsibility/>. Accessed $12 / 21 / 2018$.

24. Christman, J., \& Anderson, N. (Eds.). (2005). Autonomy and the challenges to liberalism. Cambridge: Cambridge University Press.

25. Bolton, D., \& Banner, N. (2012). Does mental disorder involve a loss of personal autonomy? In L. Radoilska (Ed.), Autonomy and mental disorder (pp. 77-99). Oxford: Oxford University Press.

26. Beauchamp, T. L., \& Childress, J. F. (2012). Principles of biomedical ethics (7th ed.). New York, NY: Oxford University Press.

27. Marmot, M. (2006). Status syndrome: A challenge to medicine. Journal of the American Medical Association, 295(11), 1304-1307.

28. Hegel, G. W. (2009). Phenomenology of Spirit, (J. B. Baillie, Trans.). Lawrence, KS: Digireads.com. Original publication 1807.

29. Iser, M. (2013). Recognition. In E.N. Zalta (Ed.), The stanford encyclopedia of philosophy (Fall 2013 Edition), URL $=<$ https://plato.stanford.edu/ archives/fall2013/entries/recognition/>. Accessed 12/21/2018.

30. Taylor, C. (1992). The politics of recognition. In A. Gutmann (Ed.), Multiculturalism: Examining the politics of recognition (pp. 25-73). Princeton: Princeton University Press.

31. Williams, R. R. (1992). Recognition: Fichte and Hegel on the other. Albany, NY: SUNY Press. 
32. Lasswell, H. (1936). Politics: Who gets what, when, how. New York: Whittlesey House.

33. Mackenzie, C., \& Stoljar, N. (Eds.). (2000). Relational autonomy: Feminist perspectives on autonomy, agency and the social self. New York: Oxford University Press.

34. Delgado, R., \& Stefancic, J. (2017). Critical race theory (3rd ed.). New York: New York University Press.

35. Loomba, A. (2015). Colonialism/Postcolonialism (3rd ed.). London: Routledge.

36. Fricker, M. (2007). Epistemic injustice: Power and the ethics of knowing. Oxford: Oxford University Press.

37. Dotson, K. (2011). Tracking epistemic violence, tracking practices of silencing. Hypatia, 26(2), 236-257. https://doi.org/10.1111/j.15272001.2011.01177.x.

38. Cockerham, W. C. (2007). Social causes of health and disease. Cambridge: Polity Press.

39. Kelly, M. P., Kelly, R. S., \& Russo, F. (2014). The integration of social, behavioral, and biological mechanisms in models of pathogenesis. Perspectives in Biology and Medicine, 57(3), 308-328.

40. Krieger, N. (1994). Epidemiology and the web of causation: Has anyone seen the spider? Social Science and Medicine, 39(7), 887-903.

41. Krieger, N. (2008). Proximal, distal, and the politics of causation: What's level got to do with it? American Journal of Public Health, 98(2), 221-230.

42. Marmot, M. (2005). Remediable or preventable social factors in the aetiology and prognosis of medical disorders. In P. D. White (Ed.), Biopsychosocial Medicine: An integrated approach to understanding illness (pp. 39-58). New York: Oxford University Press.

43. Galea, S., Riddle, M., \& Kaplan, G. A. (2010). Causal thinking and complex system approaches in epidemiology. International Journal of Epidemiology, 39(1), 97-106. https://doi.org/10.1093/ije/dyp296.

44. Heath, J. (2015). Methodological individualism. In E.N. Zalta (Ed.), The stanford encyclopedia of philosophy (Spring 2015 Edition), URL $=<$ https:// plato.stanford.edu/archives/spr2015/entries/methodological-individualism/>. Accessed 12/21/2018.

45. Zahle, J. (2016). Methodological holism in the social sciences. In E.N. Zalta (Ed.), The stanford encyclopedia of philosophy (Summer 2016 Edition), URL $=<$ https://plato.stanford.edu/archives/sum2016/entries/holism-social/ $>$. Accessed 12/21/2018.

46. List, C., \& Spiekermann, K. (2013). Methodological individualism and holism in political science: A reconciliation. American Political Science Review, 107(4), 629-643. https://doi.org/10.1017/S0003055413000373. 
47. UK Research Councils. (2017). Widening cross-disciplinary research for mental health. http://www.rcuk.ac.uk/documents/documents/cross-disciplinary-mental-health-research-agenda-pdf/. Accessed December 21, 2018.

48. Moffitt, T. E., Caspi, A., \& Rutter, M. (2005). Strategy for investigating interactions between measured genes and measured environments. Archives of General Psychiatry, 62(5), 473-481. https://doi.org/10.1001/ archpsyc.62.5.473.

49. Purcell, S. (2002). Variance components models for gene-environment interaction in twin analysis. Twin Res, 5(6), 554-571. https://doi. org/10.1375/136905202762342026.

50. Atkinson, N. J., \& Urwin, P. E. (2012). The interaction of plant biotic and abiotic stresses: From genes to the field. Journal of Experimental Botany, 63(10), 3523-3543.

51. Weaver, I. C. G., Cervoni, N., Champagne, F. A., D'Alessio, A. C., Sharma, S., Seckl, J. R., et al. (2004). Epigenetic programming by maternal behavior. Nature Neuroscience, 7, 847. https://doi.org/10.1038/nnl276.

52. Robinson, G. E., Fernald, R. D., \& Clayton, D. F. (2008). Genes and social behavior. Science, 322(5903), 896-900.

53. Anacker, C., O’Donnell, K. J., \& Meaney, M. J. (2014). Early life adversity and the epigenetic programming of hypothalamic-pituitary-adrenal function. Dialogues in Clinical Neuroscience, 16(3), 321-333.

54. Talmud, P. J. (2007). Gene-environment interaction and its impact on coronary heart disease risk. Nutrition, Metabolism and Cardiovascular Diseases, $17(2), 148-152$.

55. McGuinness, D., McGlynn, L. M., Johnson, P. C., MacIntyre, A., Batty, G. D., Burns, H., et al. (2012). Socio-economic status is associated with epigenetic differences in the pSoBid cohort. International Journal of Epidemiology, 41(1), 151-160. https://doi.org/10.1093/ije/dyr215.

56. Manuck, S. B., \& McCaffery, J. M. (2014). Gene-environment interaction. Annual Review of Psychology, 65, 41-70. 
Open Access This chapter is licensed under the terms of the Creative Commons Attribution 4.0 International License (http://creativecommons.org/licenses/ by $/ 4.0 /$ ), which permits use, sharing, adaptation, distribution and reproduction in any medium or format, as long as you give appropriate credit to the original author(s) and the source, provide a link to the Creative Commons license and indicate if changes were made.

The images or other third party material in this chapter are included in the chapter's Creative Commons license, unless indicated otherwise in a credit line to the material. If material is not included in the chapter's Creative Commons license and your intended use is not permitted by statutory regulation or exceeds the permitted use, you will need to obtain permission directly from the copyright holder.

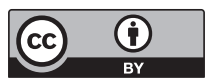

